\title{
Nível Crítico de dano de Papuã em Feijão-Comum ${ }^{1}$
}

\author{
Critical Density of Alexander Grass in Common Bean
}

\begin{abstract}
KALSING, A. ${ }^{2}$ e VIDAL, R.A. ${ }^{3}$
RESUMO - Os objetivos do presente trabalho foram estimar níveis críticos de dano de papuã (Urochloa plantaginea) em feijão-comum, em situações onde a planta daninha foi manejada precocemente e ocorreu reinfestação, e avaliar as alterações que sofre em decorrência de cultivares de feijão-comum e variáveis explicativas da infestação. Foram realizados dois experimentos em campo, em Eldorado do Sul, RS, sendo um com o cultivar UFT-06 (grupo Carioca) e o outro com o cultivar IPR Graúna (grupo Preto). Os niveis de infestação de papuã foram obtidos com quatro herbicidas residuais, aplicados em duas doses cada, mais testemunhas com e sem controle de papuã. A densidade, massa fresca e massa seca do papuã foram avaliadas no início e no final do período crítico de prevenção da interferência, e o rendimento de grãos da cultura foi avaliado por ocasião da colheita. O nível crítico de dano de papuã não teve valor elevado nessa situação $(0,4$ a $0,7 \%)$; todavia, pode haver benefício em controlá-lo de acordo com a infestação e o custo de controle. O nivel crítico de dano foi sempre maior para o cultivar IPR Graúna, em relação ao UTF-06. A densidade e as massas fresca e seca das plantas de papuã explicaram adequadamente a perda de produção de feijão-comum pelo modelo de regressão não linear da hipérbole retangular.
\end{abstract}

Palavras-chave: Phaseolus vulgaris, Urochloa plantaginea, Brachiaria plantaginea, nível de dano econômico, manejo integrado.

\begin{abstract}
The objectives were to estimate the magnitude of the critical density of alexander grass (Urochloa plantaginea) in common bean, in cases where this weed was managed in early stage of crop and occurred reinfestation, and the changes its suffer as a result of different cultivars and variables of alexander grass infestation. Two field experiments were conducted at Eldorado do Sul, RS/ Brazil, one cultivated with the bean cultivar UFT-06 (red group) and the other IPR Grauna (black group). The levels of alexander grass infestation were obtained with four residual herbicides, applied at two rates in crop preemergence, and plots with and without weed control. The density, fresh mass and dry mass of alexander grass were evaluated during the critical weed-bean competition period, and the crop yield was evaluated at harvest. The critical density of alexander grass in common bean was not high in this situation (0.4 to 0.7\%); however, there may be benefit in weed control according to the level of infestation and cost control. The critical density was always higher for the cultivar IPR Graúna, in relation to UTF-06. The density, fresh mass and dry mass of alexander grass explained adequately the grain yield loss of common bean crop by the nonlinear hyperbolic regression model.
\end{abstract}

Keywords: Phaseolus vulgaris, Urochloa plantaginea, Brachiaria plantaginea, economic threshold, integrated weed management.

Recebido para publicação em 28.9.2012 e aprovado em 26.2.2013.

2 Instituto Rio Grandense do Arroz - IRGA, Cachoeirinha-RS, Brasil, < augusto@fundacaoirga.org.br>; ${ }^{3}$ Universidade Federal do Rio Grande do Sul - UFRGS, Porto Alegre-RS, Brasil.

Planta Daninha, Viçosa-MG, v. 31, n. 4, p. 843-850, 2013 


\section{INTRODUÇÃO}

O manejo integrado de pragas foi introduzido na agricultura a partir da década de 1950 , com vistas a mitigar os efeitos colaterais advindos do uso errôneo de pesticidas (Smith $\&$ Allen, 1954). A aplicação desse modelo de gestão pressupõe a adoção de critérios para a decisão sobre o controle de pragas, entre os quais se destacam os diferentes níveis de dano ou de prejuízo. No início, esses níveis foram desenvolvidos para o manejo de insetos (Stern et al., 1959) e, após décadas, para o de plantas daninhas, com adequações nas formas de definição e uso. Desde então, distintos níveis de dano têm sido propostos para subsidiar as decisões do controle de plantas daninhas em sistemas de manejo integrado (Portugal \& Vidal, 2009).

O nível crítico de dano (NCD) é um dos critérios usados para subsidiar a decisão do controle de plantas daninhas, que equivale ao dano individual dessas espécies sobre o rendimento da cultura (Vidal et al., 2010a). Esse nivel de dano incorpora os conceitos de densidade crítica e período crítico, uma vez que os aspectos populacional e temporal são mutuamente dependentes (Portugal, 2010). Com ele, pode-se estimar por inferência qual a densidade de infestantes no período crítico de prevenção da interferência (PCPI) que causa perda expressiva de produção da cultura. Um aspecto que o diferencia dos demais niveis de dano de pragas é que o NCD não considera variáveis econômicas, o que ocorre, por exemplo, com o nivel de dano econômico.

O feijão-comum (Phaseolus vulgaris) é uma cultura com enorme importância para a agricultura e para a sociedade brasileira por, pelo menos, quatro motivos: alimentar, cultural, econômico e social. No Brasil, a sua produtividade média sempre esteve abaixo de $1.000 \mathrm{~kg} \mathrm{ha}^{-1}$, embora nas lavouras tecnificadas sejam obtidos valores até três vezes superiores (IBGE, 2012). Muitos fatores têm sido aventados para a ocorrência dessa situação, entre os quais destaca-se a interferência negativa imposta por plantas daninhas à cultura (Vincensi et al., 2011). O feijãocomum é muito cultivado em pequenas e médias propriedades no País, onde o manejo dessas espécies nem sempre ocorre na intensidade correta ou no momento mais adequado.

Nas condições de cultivo das regiões Sul, Sudeste e Centro-Oeste do Brasil, o papuã (Urochloa plantaginea) é uma das principais plantas daninhas infestantes das lavouras de feijão-comum. Em muitos casos, exerce elevado grau de prejuízo sobre a produtividade e lucratividade dessa cultura, especialmente quando ocorre em elevada densidade populacional. De fato, a presença dessa espécie daninha em densidade de 25 plantas $\mathrm{m}^{-2}$ gerou perda de produtividade do feijoeiro comum variando entre 5 e 70\% (Passini, 2001). Desse modo, ações de pesquisa que visem estimar a magnitude do NCD de papuã em feijão-comum são necessárias para subsidiar as estratégias de controle dessa planta daninha.

O controle do papuã depende basicamente do nivel tecnológico utilizado pelo produtor de feijão-comum e, no caso das pequenas e médias propriedades, é comumente realizado com capinas manuais. A capina é um dos trabalhos mais árduos e frustrantes a que se submete o agricultor, pois é cansativa e desgastante e precisa ser repetida com a reinfestação da área (Vidal et al., 2010b). Em geral, a capina manual é realizada tão logo as plantas daninhas começam a emergir na área, havendo, em muitas situações, dúvidas sobre a necessidade de novo repasse. De posse do nível de infestação da área e da magnitude do NCD do papuã, o produtor poderia decidir tecnicamente sobre a viabilidade de uma segunda capina da lavoura. O uso de herbicidas residuais proveria dados para estimar o NCD de papuã nessa condição, ocasionando fluxos de emergência da planta daninha após o estabelecimento da cultura.

Os objetivos deste trabalho foram estimar niveis críticos de dano de papuã no feijoeiro comum, em situações onde a planta daninha foi manejada precocemente e ocorreu reinfestação da cultura, e avaliar as alterações que ela sofre em decorrência de cultivares de feijão-comum e variáveis da infestação.

\section{MATERIAL E MÉTODOS}

Foram realizados, nos anos de 2008 e 2009, dois experimentos em campo em Eldorado do 
Sul-RS, em área pertencente à Faculdade de Agronomia da Universidade Federal do Rio Grande do Sul (UFRGS). Esse municipio situase na região ecoclimática da Depressão Central do RS, com clima do tipo subtropical úmido de verão e precipitação média de $1.400 \mathrm{~mm}$ ano $^{-1}$. O solo da área experimental é classificado como Argissolo Vermelho distrófico (Streck et al., 2008) e teve, na análise laboratorial, $28 \%$ de argila, 1,5\% de $\mathrm{MO}$ e $\mathrm{pH}$ igual a 6,0. A área dos experimentos vinha sendo manejada em sistema de preparo há mais de 20 anos, com cultivo de soja e azevém, respectivamente, nas estações estival e hibernal. Os valores diários coletados para a precipitação pluvial e a temperatura do ar durante o ciclo de desenvolvimento da cultura estão representados na Figura 1A, B.

Um dos dois experimentos foi conduzido com o cultivar UFT 06 (grupo Carioca), e o outro, com o cultivar IPR Graúna (grupo Preto). Os experimentos foram implantados em áreas contíguas e manejados de forma análoga. $\mathrm{O}$ feijoeiro comum foi semeado após duas operações de gradagem do solo, em outubro de 2008, com linhas espaçadas de 0,40 m e uma população de 200.000 plantas ha-1. A adubação do solo foi feita pela distribuição nas linhas de semeadura de $400 \mathrm{~kg} \mathrm{ha}^{-1}$ da fórmula 05-2030 , o que aportou $20 \mathrm{~kg} \mathrm{ha}^{-1} \mathrm{de} \mathrm{N}, 80 \mathrm{~kg} \mathrm{ha}^{-1} \mathrm{de}$ $\mathrm{P}_{2} \mathrm{O}_{5}$ e $120 \mathrm{~kg} \mathrm{ha}^{-1}$ de $\mathrm{K}_{2} \mathrm{O}$. Além disso, foram realizadas adubações com $60 \mathrm{~kg} \mathrm{ha}^{-1}$ de $\mathrm{N}$ e $15 \mathrm{~kg} \mathrm{ha}^{-1}$ de $\mathrm{K}_{2} \mathrm{O}$ quando as plantas de feijãocomum atingiram os estádios $\mathrm{V}_{3}$ e $\mathrm{V}_{6}$ (Gepts \& Fernandez, 1982).

O delineamento experimental utilizado foi o completamente casualizado com uma repetição por tratamento. Os tratamentos avaliados constaram de diferentes niveis de infestação de papuã na cultura, cuja emergência ocorreu somente após o estabelecimento do feijoeiro comum. Para isso, usaram-se quatro herbicidas residuais, aplicados em duas doses $\left(\mathrm{kg} \mathrm{ha}^{-1}\right)$ : pendimethalin e trifluralin $(1,6$ e 2,4); dimethenamid e S-metolachlor (1,2 e $1,4)$; e mais testemunhas com e sem infestação permanente da planta daninha na cultura. Essas situações possibilitaram a emergência de densidades de papuã nas 30 unidades experimentais de cada experimento, conforme método descrito em Vidal et al. (2010c). Os herbicidas foram aspergidos logo após a semeadura do feijoeiro comum, utilizando-se pulverizador costal de precisão, com volume de calda equivalente a $180 \mathrm{~L} \mathrm{ha}^{-1}$. A aplicação foi feita em período com temperatura do ar amena $\left(18^{\circ} \mathrm{C}\right)$, umidade relativa do ar elevada (81\%) e umidade volumétrica do solo na capacidade de campo.

As unidades experimentais corresponderam a parcelas com dimensões de 10,0 x 2,0 $\mathrm{m}$, nas quais foram aspergidos, de forma totalmente aleatória, os diferentes herbicidas residuais. As avaliações foram feitas no início e no final do período crítico de prevenção da interferência (PCPI), o que correspondeu a 20 e 40 dias após a emergência (DAE) da cultura. Nessas datas foram avaliadas, em área de $0,5 \mathrm{~m}^{2}$, a densidade de plantas e as massas fresca e seca do papuã, sendo os dados convertidos

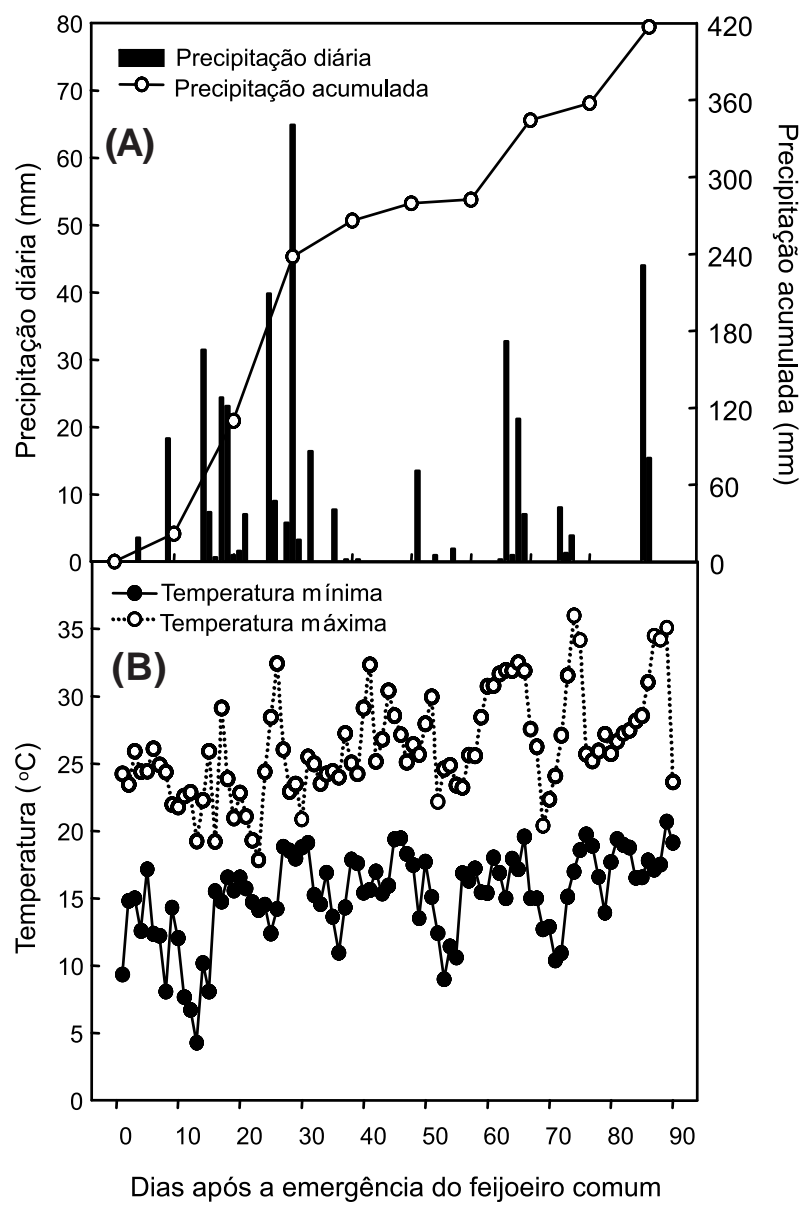

Figura 1 - Dados pluviométricos (A) e de temperatura do ar (B) observados entre a semeadura e a colheita do feijoeiro comum. 
em plantas $\mathrm{m}^{-2}$ e $\mathrm{g} \mathrm{m}^{-2}$, respectivamente. As massas fresca e seca foram avaliadas com o mesmo material, sendo a primeira aferida logo após a coleta das plantas e, a segunda, após a desidratação destas em estufa a $60{ }^{\circ} \mathrm{C}$. Também, por ocasião da colheita da cultura, avaliou-se o rendimento de grãos de feijãocomum em área de $4,8 \mathrm{~m}^{2}$, sendo os dados expressos na umidade-padrão de $13 \%$.

No início, os dados obtidos de rendimento de grãos foram ponderados em valor percentual relativamente à situação sem a presença de papuã, separadamente para cada cultivar testado. Posteriormente, os dados foram submetidos à análise de variância pelo teste $\mathrm{F}$, utilizando $5 \%$ de probabilidade do erro experimental como limite para a detecção de significância estatística. No final, análises de regressão foram feitas para ajustar funções de resposta das perdas percentuais de rendimento de grãos às diferentes variáveis da infestação de papuã. Os dados foram ajustados ao modelo não linear da hipérbole retangular (Cousens, 1985) e expressos em termos matemáticos, conforme descrito a seguir pela equação 1 :

$$
Y=[(a * X) /(b+X)]
$$

em que $Y$ e $X$ são os valores das variáveis dependente e independente, respectivamente; $a$ é o valor da assintota de máximo valor; e $b$ é o valor do nível de infestação de papuã que equivale a $50 \%$ da assintota de máximo valor.

O nível crítico de dano (NCD) do papuã no feijoeiro comum foi obtido pela razão entre os parâmetros $a$ e $b$ da equação 1 e estima o impacto de cada planta no rendimento da cultura (Vidal et al., 2010a). O ajuste dos dados foi realizado com o apoio do programa SigmaPlot 10.0 (SigmaPlot, 2007), que fornece a magnitude do erro-padrão da estimativa de cada parâmetro.

\section{RESULTADOS E DISCUSSÃO}

O uso de herbicidas residuais e a infestação natural da área experimental possibilitaram a emergência de diferentes densidades populacionais de papuã entre as unidades experimentais. De fato, observou-se que a densidade de plantas da infestante variou de zero a mais de 1.000 plantas $\mathrm{m}^{-2}$ entre as parcelas, em ambos os cultivares testados (Figuras 2 e 3). Convém destacar que não se notaram quaisquer sintomas visuais de injúrias nas plantas de feijão em nenhuma das parcelas onde foram aspergidos os distintos herbicidas residuais. Esses resultados, aliado ao ajuste das curvas, indicam que grande parte da variabilidade do rendimento de grãos esteve associada aos diferentes níveis de infestação com papuã.

Os dados de densidade, massa fresca e massa seca da parte aérea das plantas de papuã apresentaram ajuste adequado ao modelo da hipérbole retangular, com valores de $\mathrm{R}^{2}$ entre 0,82 e 0,98 (Tabela 1). Esses resultados imprimem maior segurança na estimativa do cálculo do NCD, pois a porcentagem de perdas explicada pelo modelo foi sempre superior a $82 \%$. Verifica-se que a qualidade do ajuste variou com o cultivar de feijãocomum, a época de avaliação da infestante e a variável explicativa da infestação de papuã na cultura. Por exemplo, para as datas de avaliação, a avaliação feita aos $20 \mathrm{DAE}\left(\mathrm{R}^{2}=0,86\right)$ apresentou menor ajuste ao modelo quando comparada à de $40 \mathrm{DAE}\left(\mathrm{R}^{2}=0,95\right)$.

Os valores do parâmetro $a$ foram geralmente superestimados pelo modelo, com perdas de produção superiores a $100 \%$, exceto nas avaliações aos 20 DAE com o cultivar IPR Graúna (Tabela 1). Isso mostra que os maiores níveis de infestação nos experimentos nem sempre foram suficientes para simular adequadamente a perda máxima de rendimento de grãos. Uma alternativa para contornar essa situação seria limitar a perda máxima de produtividade em $100 \%$, o que também modificaria a magnitude dos demais parâmetros da equação. Contudo, optou-se por manter os valores da assíntota máxima superestimados para preservar a integridade da magnitude do parâmetro $b$ e da estimativa do NCD do papuã.

Com relação ao parâmetro $b$, verifica-se que o seu valor diferiu numericamente entre os cultivares de feijão-comum e as datas de avaliação da infestação do papuã, nas três variáveis avaliadas (Tabela 1). Por exemplo, para a densidade de plantas, aferida aos $20 \mathrm{DAE}$, o seu valor foi de 127 e 210 plantas $\mathrm{m}^{-2}$ de papuã, para IPR Graúna e UTF-06, respectivamente. A mesma análise, realizada com a massa seca, mostra que o valor do parâmetro 


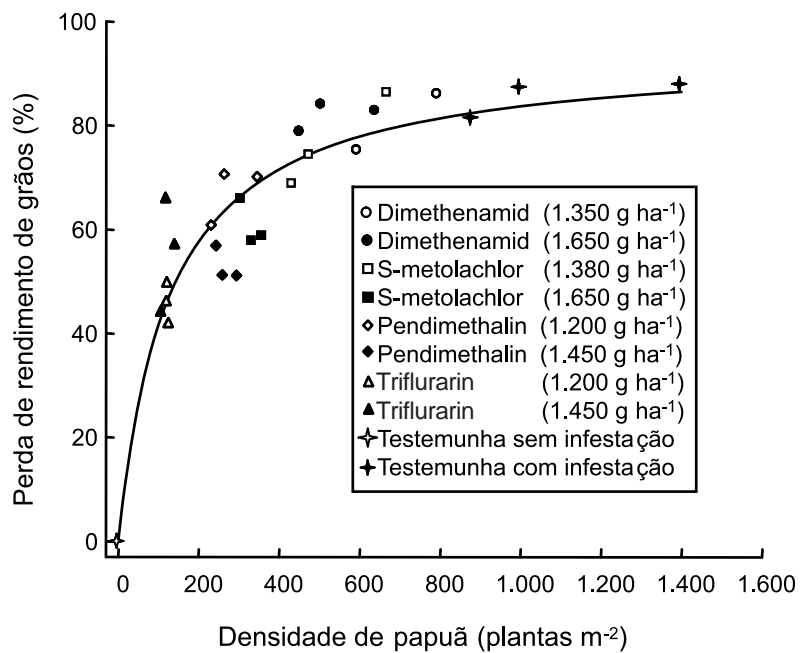

1/ Rendimento de grãos máximo: $2.618 \mathrm{~kg} \mathrm{ha}^{-1}$.

Figura 2 - Perda de rendimento ${ }^{1 /}$ de grãos do cultivar de feijão-comum IPR Graúna em função da densidade de plantas de papuã, avaliada aos 20 dias após a emergência da cultura (Equação na Tabela 1).

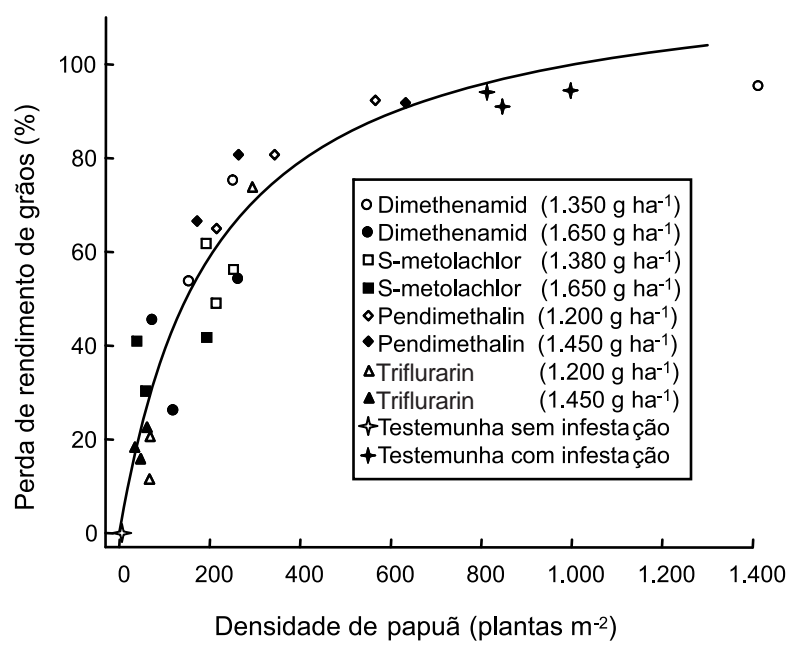

1/ Rendimento de grãos máximo: $1.710 \mathrm{~kg} \mathrm{ha}^{-1}$.

Figura 3 - Perda de rendimento ${ }^{\underline{1}}$ de grãos do cultivar de feijão-comum UTF-06 em função da densidade de plantas de papuã, avaliada aos 20 dias após a emergência da cultura (Equação na Tabela 1).

Tabela 1 - Valores dos parâmetros da equação do modelo hiperbólico simples para a perda de rendimento de grãos de dois cultivares de feijão-comum em resposta a variáveis explicativas da infestação de papuã na cultura, em duas épocas de avaliação

\begin{tabular}{|c|c|c|c|c|c|c|}
\hline \multirow{2}{*}{ Cultivar } & \multirow{2}{*}{$\mathrm{DAE}^{1 /}$} & \multicolumn{2}{|c|}{ Parâmetros da equação } & \multirow{2}{*}{$\mathrm{r}^{2}$} & \multirow{2}{*}{$\mathrm{F}$} & \multirow{2}{*}{$\mathrm{NCD}^{2 /}$} \\
\hline & & $\mathrm{a}$ & $\mathrm{b}$ & & & \\
\hline \multicolumn{7}{|c|}{ Densidade de plantas de papuã } \\
\hline IPR Graúna & 20 & $94,3 \pm 1,5$ & $127,1 \pm 7,4$ & $0,91^{\text {** }}$ & $312,2^{* *}$ & $0,7 \pm 0,2$ \\
\hline UTF-06 & 20 & $120,9 \pm 2,9$ & $210,2 \pm 12,3$ & $0,90^{* *}$ & $262,7^{* *}$ & $0,6 \pm 0,2$ \\
\hline IPR Graúna & 40 & $101,6 \pm 1,1$ & $181,1 \pm 6,1$ & $0,97^{* *}$ & $1.029,4^{* *}$ & $0,6 \pm 0,1$ \\
\hline UTF-06 & 40 & $137,8 \pm 3,0$ & $372,4 \pm 21,6$ & $0,94^{* *}$ & $435,8^{* *}$ & $0,4 \pm 0,2$ \\
\hline \multicolumn{7}{|c|}{ Massa fresca da parte aérea de papuã } \\
\hline IPR Graúna & 20 & $82,7 \pm 1,4$ & $3,7 \pm 0,3$ & $0,84^{* *}$ & $156,3^{* *}$ & $22,4 \pm 4,8$ \\
\hline UTF-06 & 20 & $108,1 \pm 2,7$ & $8,6 \pm 0,6$ & $0,83^{* *}$ & $141,4^{* *}$ & $12,6 \pm 2,5$ \\
\hline IPR Graúna & 40 & $117,7 \pm 1,3$ & $91,5 \pm 2,5$ & $0,98^{* *}$ & $1.863,5^{* *}$ & $1,3 \pm 0,1$ \\
\hline UTF-06 & 40 & $325,8 \pm 35,0$ & $643,0 \pm 90,1$ & $0,91^{* *}$ & $296,6^{* *}$ & $0,5 \pm 0,3$ \\
\hline \multicolumn{7}{|c|}{ Massa seca da parte aérea de papuã } \\
\hline IPR Graúna & 20 & $83,3 \pm 1,4$ & $1,0 \pm 0,1$ & $0,85^{* *}$ & $159,4^{* *}$ & $83,3 \pm 19,6$ \\
\hline UTF-06 & 20 & $108,0 \pm 2,7$ & $2,4 \pm 0,2$ & $0,82^{* *}$ & $134,8^{* *}$ & $45,0 \pm 8,5$ \\
\hline IPR Graúna & 40 & $117,9 \pm 1,3$ & $25,8 \pm 0,7$ & $0,98^{* *}$ & $1.717,6^{* *}$ & $4,6 \pm 0,4$ \\
\hline UTF-06 & 40 & $324,3 \pm 35,2$ & $178,3 \pm 25,3$ & $0,91^{* *}$ & $286,4^{* *}$ & $1,8 \pm 0,9$ \\
\hline
\end{tabular}

${ }^{1 /}$ Dias após a emergência da cultura do feijão-comum. ${ }^{2 /}$ Nível crítico de dano do papuã na cultura do feijão-comum. ${ }^{* *}$ Valor significativo a $1 \%$ de probabilidade do erro experimental.

b equivaleu a 1,0 e $2,4 \mathrm{~g} \mathrm{~m}^{-2}$ de papuã, para os mesmos cultivares, respectivamente. Isso demonstra que os dois cultivares de feijãocomum testados no presente trabalho responderam de forma distinta ao incremento da infestação de papuã na cultura.
O valor do NCD, obtido pela razão entre os parâmetros $a$ e $b$, variou de 0,4 a 0,7 para densidade; 0,5 a 22,4 para massa fresca; e 1,8 a 83,3 para massa seca das plantas de papuã (Tabela 1). Os NCDs estimados com base na densidade de plantas não diferiram 
numericamente entre si, enquanto aqueles calculados com base nas massas fresca ou seca se distinguiram. Nesses casos, os NCDs foram maiores para o cultivar IPR Graúna do que para UTF-06, assim como foram superiores na avaliação realizada aos $20 \mathrm{DAE}$, em relação aos 40 DAE. Esse resultado indica que a intensidade do impacto do papuã no início do PCPI do feijoeiro comum foi superior, em comparação ao impacto no final desse período.

Na discussão dos resultados a seguir será dada maior atenção para a variável densidade de plantas, em razão de ser a mais usada em experimentos com níveis de dano de infestantes. Os NCDs estimados com essa variável tiveram magnitude sempre abaixo de 1,0, o que indica baixo a médio efeito individual da espécie sobre o feijoeiro comum (Tabela 1). Essa classificação é baseada em revisões feitas por Zimdahl (2004) e Vidal et al. (2010a), que avaliam o NCD como baixo $(0,1-0,5)$, mediano $(0,5-1,0)$ e elevado $(>1,0)$. Contudo, isso não significa que a espécie não cause quedas acentuadas de produtividade, pois se deve sempre considerar também o nível de infestação de papuã na lavoura. De fato, foi observada neste trabalho redução de mais de $90 \%$ do potencial de rendimento da cultura nas situações com as maiores densidades de papuã (Figuras 2 e 3 ).

Não foram encontradas pesquisas disponiveis na literatura científica sobre a quantificação do NCD de papuã ou outras espécies de plantas daninhas na cultura de feijão-comum no Brasil. Em outros locais, como nos sistemas de cultivo dos EUA, o dano individual de Setaria viridis no feijoeiro comum causou perda de rendimento entre 1,9 e 3,3\% (Mesbah et al., 2004). Em outro estudo realizado na mesma condição com a espécie daninha Digitaria sanguinalis, os NCDs estimados situaram-se entre 9,3 e 38,7\% (Aguyoh \& Masiunas, 2003). No entanto, nessas duas pesquisas a densidade das plantas daninhas foi mantida fixa do início até o fim do ciclo da cultura, diferentemente do método usado no presente trabalho.

Uma das dificuldades da comparação entre resultados de pesquisas de avaliação do NCD de plantas daninhas, como ora discutido, está no fato de esse limiar variar tanto no espaço como no tempo, pois diversos fatores influenciam a estimativa da sua magnitude (Kalsing $\&$ Vidal, 2010). Entre esses fatores, destacamse com relevância: o agroecossistema (Pester et al., 2000), o preparo do solo (Cardina et al., 1995), o arranjo de plantas (Agostinetto et al., 2005), a adubação (Cathcart \& Swanton, 2003), o uso de herbicida residual (Vidal et al., 2010c) e a época da emergência da cultura em relação às plantas daninhas (Rizzardi et al., 2003). Com efeito, todos os estudos citados confirmam que o ambiente e as práticas agrícolas possuem elevada influência na estimativa da interferência e do NCD, as quais, em algumas situações, podem ter mais importância do que as espécies cultivada e daninha.

Os baixos NCDs obtidos neste trabalho podem ser explicados por, pelo menos, dois diferentes motivos. Primeiramente, a utilização de herbicidas residuais no experimento atrasou a época de emergência do papuã e reduziu a sua habilidade competitiva com a cultura do feijão-comum. As plantas daninhas que emergem mais tarde são as menos competitivas com as culturas e, com isso, causam menor impacto no seu rendimento (Rizzardi et al., 2003). Em segundo lugar, o papuã teve baixo impacto na cultura, pois possui características morfofisiológicas dissimilares e não ocupa nicho ecológico similar no ambiente (Bianchi et al., 2006). De fato, no caso de espécies aparentadas, como arroz e capim-arroz (Galon et al., 2007) e soja e fedegoso (Voll et al., 2002), entre outras, os valores encontrados de NCD são geralmente elevados, devido ao acentuado grau de interferência das plantas daninhas.

De posse do NCD de papuã, calculado com base na densidade de plantas no início do PCPI (20 DAE), na média da produtividade de feijão na região Centro-Sul nas últimas safras $\left(1.500 \mathrm{~kg} \mathrm{ha}^{-1}\right)$ e no preço médio recebido pelo produtor de feijão na última década $\left(\mathrm{R} \$ 100\right.$ saca $\left.^{-1}\right)$, estima-se que cada planta de papuã por $\mathrm{m}^{-2}$ ocasione prejuízo de $\mathrm{R} \$ 10 \mathrm{a}$ 18 ha $^{-1}$. Isso demonstra que o dano econômico individual do papuã nessa situação não é elevado, mas que pode haver benefício em controlá-lo de acordo com o nível de infestação da área e o custo do método de controle utilizado pelo produtor de feijão-comum. A capina manual seria viável apenas nas 
áreas altamente infestadas com papuã (>20 plantas $\mathrm{m}^{-2}$ ); o uso de herbicidas já seria justificado nas áreas com baixa infestação de papuã ( $>5$ plantas $\mathrm{m}^{-2}$ ).

Os NCDs relatados são aplicáveis às situações em que se questiona a viabilidade de controle de papuã no início do PCPI do feijoeiro comum, em áreas que haviam sido capinadas ou tratadas com herbicidas residuais e ocorreu reinfestação da lavoura, de forma análoga à metodologia utilizada. Especula-se que essas condições se aproximam da realidade do pequeno e médio produtor, que implementa medidas de controle antecipadamente para não danificar as plantas do feijoeiro comum, e ocorrem novos fluxos de emergência das infestantes. Por outro lado, quando não se emprega essa estratégia de manejo, a emergência do papuã inicia-se antes ou junto com a cultura, e o valor do seu NCD deverá estar além daqueles propostos no presente trabalho para auxiliar na decisão da tomada do controle no início do PCPI.

Os cultivares de feijão-comum apresentaram habilidade competitiva diferencial com o papuã (Tabela 1), sendo verificada em todos os casos superioridade do cultivar UTF-06 em relação ao IPR Graúna. Esses resultados são semelhantes aos observados por Andrade et al. (1999) e Barroso et al. (2010), que relatam competição diferencial de genótipos de feijão com plantas daninhas. Segundo esses autores, características como hábito de crescimento, ciclo de desenvolvimento e número de ramos, entre outras, afetam a habilidade competitiva da cultura. Há, pelo menos, duas explicações para as diferença entre os dois cultivares ora avaliados. Primeiramente, UTF-06, de hábito semiereto, pode ter sombreado as plantas de papuã e se apropriado dos recursos do meio mais rapidamente do que IPR Graúna, de hábito ereto. Em segundo lugar, UTF-06 apresentou menor potencial de produtividade do que IPR Graúna e, proporcionalmente, pode ter tido menor perda de rendimento por indivíduo de papuã.

A densidade de plantas e as massas fresca e seca da parte aérea do papuã propiciaram ajuste adequado e satisfatório dos dados de perda de produção de feijão-comum (Tabela 1). De forma geral, as três variáveis explicativas avaliadas tiveram valores de coeficiente de correlação muito próximos, o que indica semelhança na qualidade do ajuste dos dados. Esses resultados coincidem com aqueles descritos por Fleck et al. (2002) e Galon et al. (2007), entre outros autores, que também observaram que a qualidade do ajuste pouco diferiu entre as variáveis densidade e massa seca das plantas daninhas. No presente trabalho, verificou-se ainda que as avaliações feitas aos 40 DAE apresentaram maior ajuste ao modelo quando comparadas às realizadas aos 20 DAE. Todavia, essa informação não é útil para a implementação de medidas de controle, uma vez que este deve ser realizado sempre por ocasião do início do PCPI (20 DAE).

Com base nos resultados obtidos e na discussão ora apresentada, conclui-se que o NCD de papuã na cultura do feijão-comum pode ser classificado como baixo a moderado $(0,4$ a $0,7 \%)$, nas áreas onde a planta daninha havia sido manejada anteriormente e ocorreu reinfestação. Nessa situação, o prejuízo econômico à cultura causado por cada planta de papuã não é alto, mas pode haver benefício em controlá-lo de acordo com o nível de infestação da área e o custo do método de controle utilizado pelo produtor de feijão-comum. Os NCDs variaram amplamente de acordo com o cultivar de feijão-comum avaliado, sendo sempre numericamente superiores para IPR Graúna do que para UTF-06. A densidade e as massas fresca e seca das plantas de papuã propiciaram ajuste adequado dos dados de perda de rendimento pelo modelo não linear da hipérbole retangular.

\section{LITERATURA CITADA}

AGOSTINETTO, D. et al. Dano econômico como critério na decisão sobre manejo de genótipos de arroz concorrentes em arroz irrigado. Pesq. Agropec. Bras., v. 40, n. 1, p. 1-9, 2005.

AGUYOH, J. N.; MASIUNAS, J. B. Interference of large crabgrass (Digitaria sanguinalis) with snap beans. Weed Sci., v. 51, n. 2, p. 171-176, 2003.

ANDRADE, C. A. B. et al. Efeito da competição com plantas daninhas em diferentes espaçamentos sobre o rendimento de três cultivares de feijão (Phaseolus vulgaris L.). Ci.

Agrotecnol., v. 23, n. 3, p. 529-539, 1999.

BARROSO, A. A. M. et al. Interferência entre espécies de planta daninha e duas cultivares de feijoeiro em duas épocas de semeadura. Bragantia, v. 69, n. 3, p. 609-616, 2010. 
BIANCHI, M. A. et al. Características de plantas de soja que conferem habilidade competitiva com plantas daninhas. Bragantia, v. 65, n. 4, p. 623-632, 2006.

CARDINA, J. et al. Velvetleaf (Abutilon theophrasti) competition and economic threshold in conventional- and notillage corn (Zea mays). Weed Sci., v. 43, n. 1, p. 81-87, 1995.

CATHCART, R. J.; SWANTON, C. J. Nitrogen management will influence threshold values of green foxtail (Setaria viridis) in corn. Weed Sci., v. 51, n. 8, p. 975-986, 2003.

COUSENS, R. A simple model relating yield loss to weed density. Ann. Appl. Biol., v. 107, n. 2, p. 239-252, 1985.

FLECK, N. G. et al. Densidade e características morfológicas de plantas de picão-preto na previsão de perdas de rendimento de grãos de soja por interferência.

Planta Daninha, v. 20, n. 2, p. 169-179, 2002.

GALON, L. et al. Estimativas das perdas de produtividade de grãos em cultivares de arroz (Oryza sativa) pela interferência do capim-arroz (Echinochloa spp.). Planta Daninha, v. 25, n. 3, p. 697-707, 2007.

GEPTS, P.; FERNÁNDEZ, F. Etapas de desarrolho de la planta de fríjol común (Phaseolus vulgaris L.). Cali: CIAT, 1982. $10 \mathrm{p}$.

INSTITUTO BRASILEIRO DE GEOGRAFIA E ESTATÍSTICA - IBGE. Banco de dados agregados - 2012. Disponível em <http://www.sidra.ibge.gov.br/bda/>. Acesso em: 5 abr. 2012.

KALSING, A.; VIDAL, R.A. Nível de dano econômico aplicado à herbologia - revisão. Pesticidas: R. Ecotoxicol. Meio Amb., v. 20, n. 1, p. 43-56, 2010.

MESBAH, A. O. et al. Common sunflower (Helianthus annaus) and green foxtail (Setaria viridis) interference in dry bean. Weed Technol., v. 18, n. 4, p. 902-907, 2004.

PASSINI, T. Competitividade e predição de perdas de rendimento da cultura de feijão quando em competição com Brachiaria plantaginea (Link) Hitchc. Piracicaba, 2001. 130 f. Tese (Doutorado em Fitotecnia) - Escola Superior de Agricultura “Luiz de Queiroz”, Piracicaba, 2001.

PESTER, T. A. et al. Secale cereale interference and economic thresholds in winter Triticum aestivum. Weed Sci., v. 48, n. 6, p. 720-727, 2000.
PORTUGAL, J. M. Nível crítico de dano (NCD) de infestantes na cultura do tomate de indústria. In: VIDAL, R. A. et al. Nível crítico de dano de infestantes em culturas anuais. Porto Alegre: Evangraf, 2010. p. 57-72.

PORTUGAL, J. M.; VIDAL, R. A. Níveis econômicos de prejuízos de plantas infestantes nas culturas agrícolas: conceitos, definições e formas de cálculo. Planta Daninha, v. 27, n. 4, p. 869-877, 2009.

RIZZARDI, M. A. et al. Nível de dano econômico como critério para controle de picão-preto em soja.

Planta Daninha, v. 21, n. 2, p. 273-282, 2003.

SIGMAPLOT - Scientific Graphing Software. Version 10.0. 2007.

SMITH, R. F.; ALLEN, W. W. Insect control and the balance of nature. Science, v. 190, n. 1, p. 38-92, 1954.

STERN, V. M. et al. The integrated control concept. Hilgardia, v. 29, n. 1, p. 81-101, 1959.

STRECK, E. V. et al. Solos do Rio Grande do Sul. Porto Alegre: Emater/RS/UFRGS, 2008. 222 p.

VIDAL, R. A. et al. Nível crítico de dano de infestantes em culturas anuais. Porto Alegre: Evangraf, 2010a. $133 \mathrm{p}$.

VIDAL, R. A. et al. Nível crítico de dano (NCD) de infestantes na cultura do feijão. In: VIDAL, R. A. et al. Nível crítico de dano de infestantes em culturas anuais. Porto Alegre: Evangraf, 2010b. p. 32-38.

VIDAL, R. A. et al. Interferência e nível de dano econômico de Brachiaria plantaginea e Ipomoea nil na cultura do feijão comum. Ci. Rural, v. 40, n. 8, p. 1675-1681, 2010c.

VINCENSI, M. M. et al. Manejo do solo e adubação nitrogenada na supressão de plantas daninhas na cultura do feijão de inverno e irrigado. Ci. Agron., v. 42, n. 3, p. 758-764, 2011.

VOLL, E. et al. Competição relativa de espécies de plantas daninhas com duas cultivares de soja. Planta Daninha, v. 20, n. 1, p. 17-24, 2002.

ZIMDAHL, R. L. Weed-crop competition: a review. 2.ed. Oxford: Blackwell Publishing, 2004. 220 p. 